\title{
Technology Development and Engineering Practice for Protection and Utilization of Water Resources in Coal Mining in Western China
}

\begin{abstract}
Shanxi, Shaanxi, Inner Mongolia, Ningxia, and Gansu (hereafter generally referred as "the Western Area") are major coal-producing areas in China due to rich coal resources and good mining conditions. However, the Western Area has a serious water shortage. The surface evaporation is huge and a great amount of mine water generated in coal mining is evaporated and lost after discharging to surface. In order to protect and utilize the water resources during large-scale coal mining in the Western Area, Shenhua Group has put forward a technological idea to store mine water in underground mined areas and successfully researched and developed the coal mine underground reservoir technology by solving the technical difficulties of water source prediction, reservoir site selection, reservoir capacity design, dam construction, safety guarantee, water quality control and so on through 20 years of exploration. Now Shenhua Group has successfully established a batch of reservoir in the Shendong Mining Area, obtaining great economic and social benefits. The technology is also extended to other western mining areas, providing an effective path for harmonic mining of coal and water resources in western China.
\end{abstract}

Keywords: Western Mining Area, coal mining, water resources, coal mine underground reservoirs

Manuscript received July 10, 2015; accepted October 28, 2015

Da-zhao Gu (ه)

State Key Laboratory of Water Resource Protection and Utilization in Coal Mining, Science \&Technology Development Department, Shenhua Group Corporation Limited, Beijing 100011, China

Email: gudz@shenhua.cc

\section{Introduction}

As the major energy source of China, coal output reached $3.87 \times 10^{9}$ tonnes in 2014 , which accounted for $66 \%$ of the country's primary energy consumption, and $46.9 \%$ of the global coal output (BP Global, 2015). According to the prediction from the Chinese Academy of Engineering, coal will still account for about $60 \%$ and about $50 \%$ of China's primary energy consumption by 2020 and 2030 (Chinese Academy of Engineering, 2012). However, a great amount of mine water will be generated in coal mining. According to statistics from National Energy Administration, mine water generated annually during coal mining is about $8 \times 10^{9}$ tonnes at present, with only about $25 \%$ utilized, and annual loss of about $6 \times 10^{9}$ tonnes, which corresponds to $60 \%$ of China's industrial and civil water deficit per year.

Due to the rich coal resources and the occurrence of ideal coal conditions, Western China is very suitable for largescale modern mining. The coal output in Shanxi, Shaanxi, Inner Mongolia, Ningxia, and Gansu (hereafter generally referred as the Western Area) rose from $0.53 \times 10^{9}$ tonnes in 2003 to $2.61 \times 10^{9}$ tonnes in 2013 , and its proportion in the whole country's coal output rose from $40 \%$ in 2003 to $71 \%$ in 2013 (China National Coal Association, 2013), which will continuously rise in the future. However, the western mining areas are seriously lacking water, and underground water resources are further damaged due to coal mining, thus aggravating the contradiction between large-scale coal mining and water resources shortage, seriously hindering regional economic and social development.

As the largest coal enterprise in the world, Shenhua Group had an output of $437 \times 10^{6}$ tonnes raw coal in 2014, $80 \%$ of which is from the Western Area. In order to protect and utilize the precious water resources in the Western Area during coal mining, while using the Shendong Mining Area as a research \& development base, Shenhua Group has developed the coal mine underground reservoir technology system. This system stores and utilizes mine water underground as a core and successfully carried out project demonstration and technology commercialization. 


\section{Background of technology development and technical idea}

\subsection{The process for mine water generation}

During underground coal mining overburden rock on the working face forms a stress field. This action causes the coal roof and the overburden rock to fall down gradually to form an overburden rock fissure field which conducts the overburden aquifer, forming a seepage field in the overburden rock. Therefore, through combined actions and development of the overburden rock stress field, the fissure field, and the seepage field, the underground water in the overburden aquifer migrates to the underground to form mine water (Figure 1). According to research statistics, about 2 tonnes of mine water can be generated as long as one tonne of coal is mined in China (He, Yang, Shao, Li, \& Wang, 2008).

Since the mine water is considered as a source of danger for underground operations, and also, for many years technology regarding underground storage of mine water storage has not been developed. Mine water is always discharged onto the surface for treatment at home and abroad. In most foreign mining areas and the eastern mining areas of China, mine water is discharged onto the surface water system after treatment, suffering a minor loss. However, in the western mining areas of China, a great amount of mine water is evaporated and lost after being discharged onto the surface.

2.2 New pathway on storage and utilization of underground mine water

In order to protect and utilize the mine water generated in coal mining, a technical idea on storage and utilization of underground mine water through coal mine underground reservoir technology has been put forward to effectively avoid its evaporation and loss during discharging. Using the Shendong Mining Area as a base, Shenhua Group carried out technology development and project demonstration on protection and utilization of water resources in coal mining in western China. The basic idea on storage and utilization of the underground mine water through coal mine underground reservoir is as follows (Figure 2):
1) Use voids of the caving rock masses in the mined area formed after coal mining as water storage space;

2) Connect the coal pillar dams around the working face with the artificial dam to form a water retaining dam;

3) Build a water transferring facility to inject into and extract from the water storage area for the mine water;

4) Perform real time monitoring on underground storage of water to guarantee production safety.

The major advantage of storage and utilization of mine water includes three aspects. Firstly, the mine water can be exempted from evaporation and loss through underground storage and application. Secondly, reservoir construction cost is largely reduced due to full use of water storage space formed in coal mining and barrier coal pillars. Thirdly, water hazards can be effectively avoided through centralized storage and real time monitoring of the mine water. However, since storage and utilization of underground water through the coal mine underground reservoir is a completely new technical idea, no existing technology can be used for reference. Thus, Shenhua Group has been carrying out a study of the basic theory on underground storage and developed key technologies of coal mine underground reservoirs in the last 20 years, forming a theoretical frame and technology system.

\section{Coal mine underground reservoir theory and technology}

\subsection{Basic theory research}

\subsection{1 "Three fields" development rule in coal mining}

To master the rule of generation and migration of the mine water in coal mining, a systematic simulation (Figure 3) and onsite research on development rule of the overburden rock stress field, the fissure field, and the seepage field has been performed. This indicates that the large-scale modern mining would inevitably result in cracks in the overburden rock to make the underground water in the aquifer seep underground to generate mine water (Gu \& Zhang, 2012). The Quaternary pore water and the bedrock fissure water are long-term stable sources of the mine water (Gu, 2012).
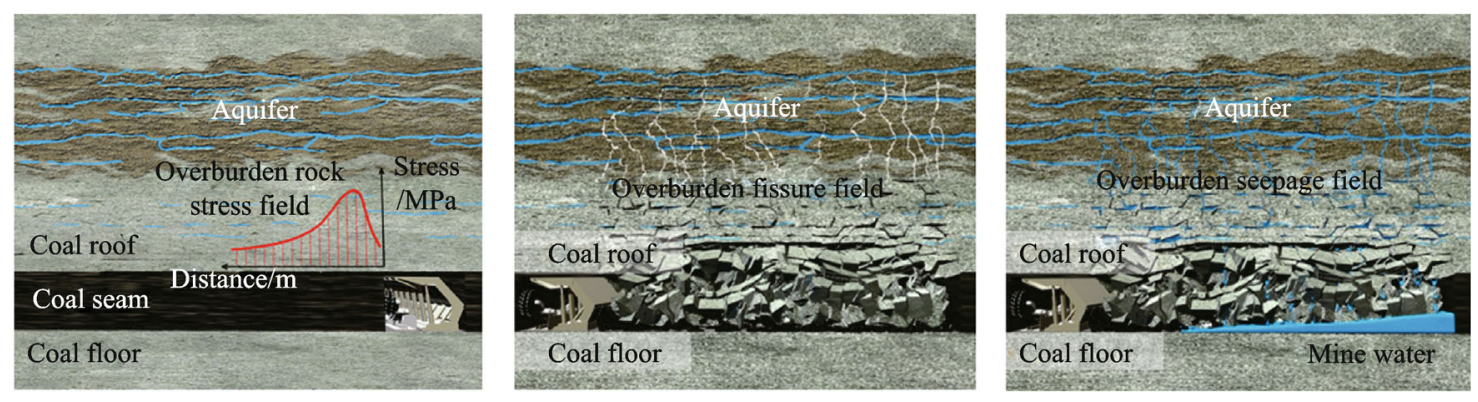

Figure 1. The process for the generation of mine water in coal mining. 


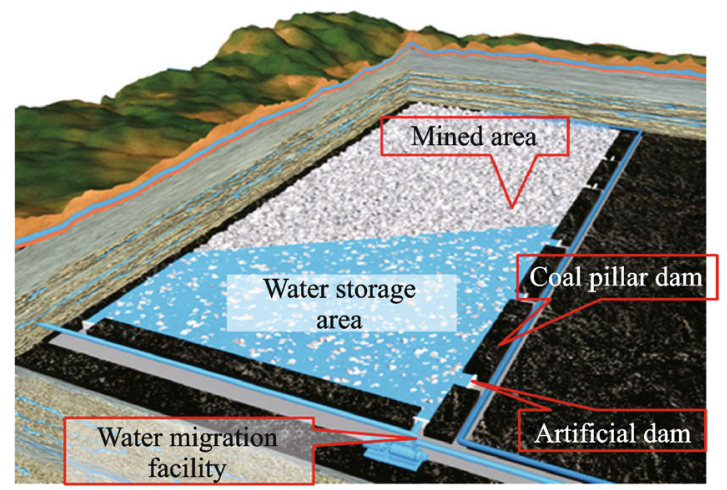

Figure 2. Technical idea sketch about coal mine underground reservoir.

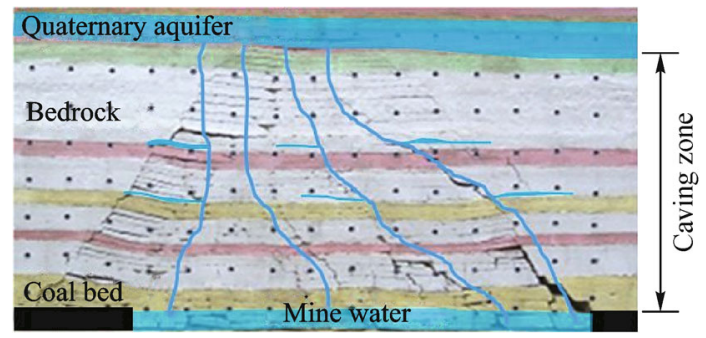

Figure 3. Physical simulation on overburden rock fissures forming water cracks for aquifer.

\subsubsection{Purification mechanism of the mine water in the mined area}

By experimental study, the purification mechanism of the mine water by rock masses in the mined area has been mastered. Suspended matter in the mine water was reduced due to the effects of filtering and precipitation of the rock masses; Organic matter (COD) in the mine water was reduced due to absorption by the rock masses; hardness of calcium and magnesium ions were reduced due to ion exchange between the rock masses and the mine water. Research has shown that the quality of the mine water can be controlled by adjusting and controlling its migration parameters in the rock masses.

3.1.3 Water storage coefficient in the mined area and its influence rule

Water storage coefficient is defined as the water reserve in the mined area per unit volume. The influential rules of the nature of the rock masses, mining technology, mine pressure and post-mining time on the storage coefficient have been studied. A physical model study on the water storage coefficient in the mined area has been performed by using a large-scale three-dimensional simulation test bench, and in combination with the pumping and drainage engineering test in the Shendong Mining Area. The water storage coefficient of the underground reservoir in the mining area is about 0.3 according to the above research, providing a basic data support for reservoir capacity design.

3.1.4 Influence of the earthquake on the structural strength of the underground reservoir dam

The Influence of earthquakes on the coal mine underground reservoir dams has been revealed by numerical and physical simulations (Figure 4). It shows that under earthquake conditions, the underground reservoir dam is much safer than the ground reservoir dam. For example, under a Ms 8.0 earthquake, the degree of safety of the underground reservoir dam in Daliuta Coal Mine is 3.83 times of that of the ground reservoir.

\subsection{Breakthrough in key technology}

\subsubsection{Mine water inflow prediction}

On the basis of understanding the effect of coal mining on the migration law of underground water, a more accurate coal mine inflow prediction model was established through long-term observation on the inflow of 242 working faces in 15 coal mines in the Shendong Mining Area. Technical support is provided for reservoir capacity design and conduction planning of underground reservoirs. For details, see Figure 5.

\subsubsection{Reservoir site selection}

In order to determine reasonable reservoir sites, observation and study were carried out on 209 hydrological holes and nearly 300 working faces in the Shendong Mining Area. Converging flow fields of underground water in coal mining were analyzed. It comes to the conclusion that the underground water converges to the mining area within the coal mine field. According to the conclusion, a site selection technology for coal mine underground reservoirs on the same coal seam, as well as the lower coal seam, has been developed. Three principles on site selections for storage of underground water were put forward: a simple geological structure and water-tightness for the water storage area, convenience for convergence of the mine water, convenience for migration of the surrounding mine water.

\subsubsection{Reservoir capacity calculation and capacity expansion} technology

The mine water is stored in the voids of the rock masses in the mined area in the coal mine underground reservoir. Reservoir capacity calculation is the core of the reservoir 


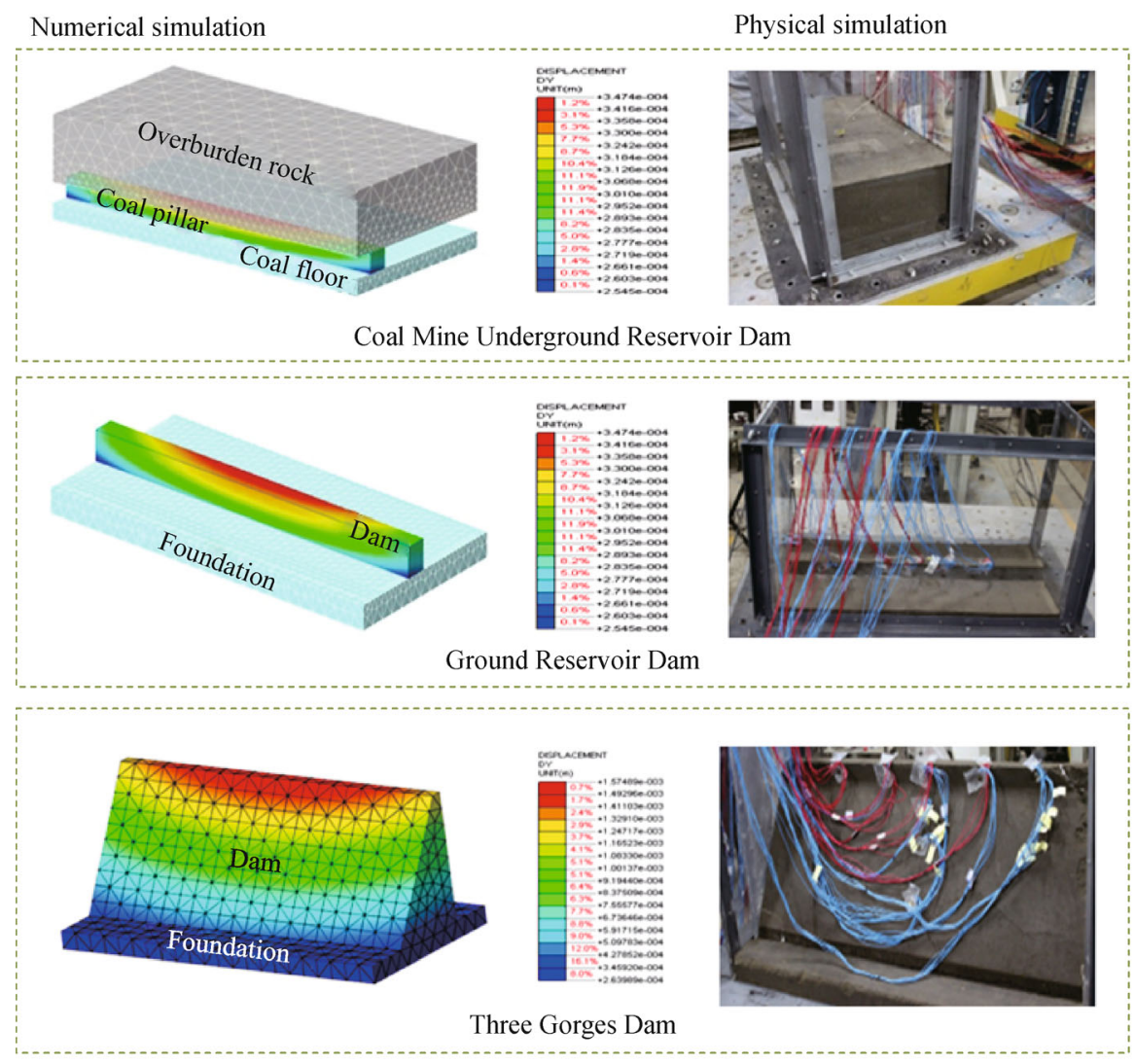

Figure 4. Numerical and physical simulations on deformation of different reservoir dams under earthquake conditions.

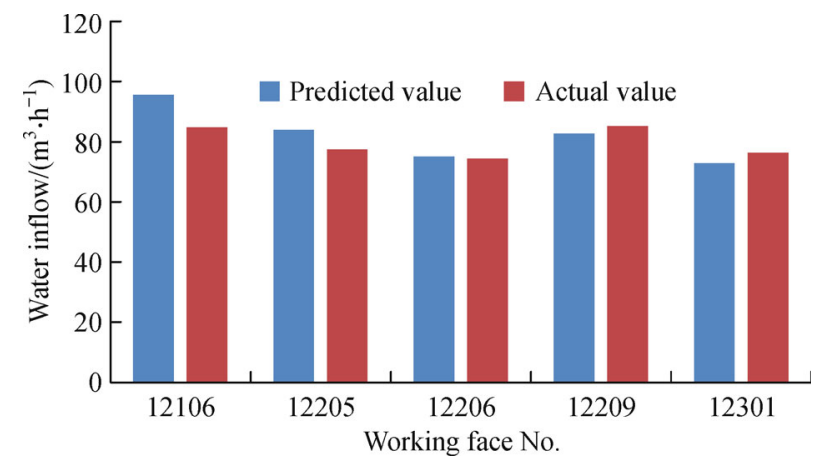

Figure 5. Comparison of predicted value and actual value of water inflow in the $1^{-2}$ coal seam of Shangwan Coal Mine.

design. The water storage coefficient in the mined area has been performed by applying a large-scale three-dimensional simulation test bench and a pumping and drainage measurement. The above tests have been performed in the Shendong Mining Area, providing engineering data support for the water storage coefficient of the underground reservoir. According to the water storage coefficient, the water level, the coal seam dip angle, and the water storage

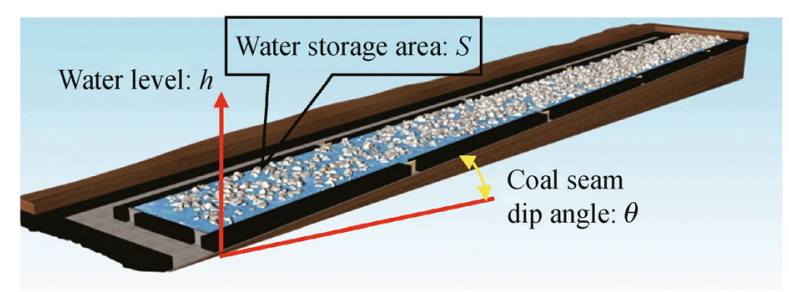

Figure 6. Sketch of reservoir capacity calculation parameters of underground reservoir.

area (Figure 6), a coal mine underground reservoir capacity calculation model has been put forward.

To improve water storage capability in the mined area, a super large working face technology (Gu, 2013a, 2013b) has been developed, resolving difficulties such as mine pressure increase, coal wall caving, complex transportation and ventilation trouble. Also, the largest working face (dimension increase from $220 \mathrm{~m} \times 4 \mathrm{~m} \times 2300 \mathrm{~m}$ to $400 \mathrm{~m}$ $\times 7 \mathrm{~m} \times 4000 \mathrm{~m}$ ) in the world has been built, which has increased water storage capability per common working face by 2 to 3 times. On that basis, several adjacent working faces are combined to an underground mine coal reservoir 


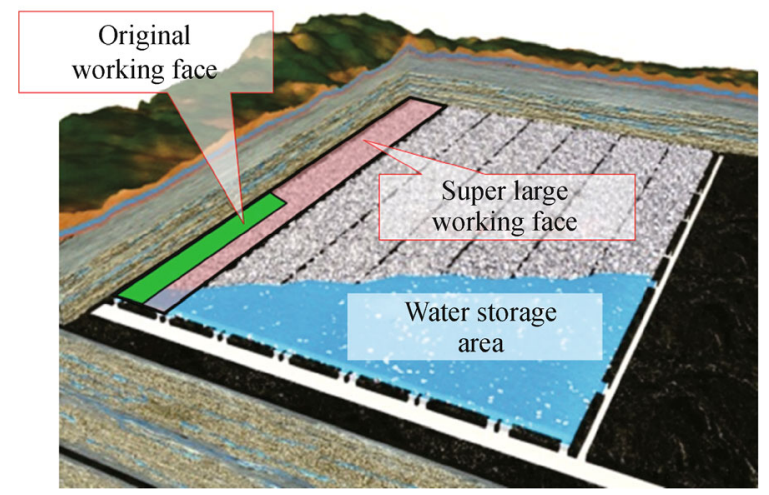

Figure 7. Sketch of underground reservoir expansion technology.

with larger water storage capability, which increased water storage capability per single mined area of the underground reservoir by 4 to 7 times (Figure 7).

\subsubsection{Dam construction}

The coal mine underground reservoir dam is composed by connecting the barrier coal pillars on the peripheries of the mined area with the artificial dam to form a water retaining dam. The dam construction is the key to constructing the underground reservoir. The coal mine underground reservoir dam has a special non-homogenous and discontinuous structure with variable sections. Meanwhile, the dam is intricately stressed and is affected by mine pressure, water pressure, mine vibration and other factors. To ensure dam safety and no water seepage, an artificial dam and coal pillar cutting and connecting process have been researched $\&$ developed (Figure 8), and special cutting equipment has also been developed. Major parameters of the underground reservoir dam such as width of the coal pillar dam, thickness of the artificial dam and the cutting depth are determined by study and analysis, and calculation methods of which are put forward. In the Shendong Mining Area, the width of the coal pillar dam is $20 \mathrm{~m}$ to $30 \mathrm{~m}$, the thickness of the artificial dam is about $1 \mathrm{~m}$, and the cutting depth is $0.3 \mathrm{~m}$ to $0.5 \mathrm{~m}$.

\subsubsection{Safety guarantee}

As the construction and the operation of the coal mine underground reservoirs are simultaneously carried out together with coal mining, the requirements for safe operation of the reservoirs are higher. Therefore, a coal mine underground reservoir safety triple-prevention and control technology (Gu, 2014) (Figure 9) have been researched \& developed: wherein the first prevention and control is to control the water levels of the reservoirs through water diversion to guarantee reservoir safety; the second prevention and control is to monitor the stress and deformation situations of the dam's weak links to guarantee dam safety; and the third prevention and control is to install the emergency drainage devices on the artificial dams. The installed emergency drainage device is used for drainage and pressure reduction under the emergency situations of mine earthquakes, ground pressure impact and the like to ensure the reservoir safety. By such triple-prevention and control technology, the safety of underground water storage can be reliably guaranteed.

\subsubsection{Water quality control}

Studies show that the purification effect of the mine water is closely related to its migration velocity and distance in the rock masses in the mined area. By controlling injection volume of the mine water and changing water injection

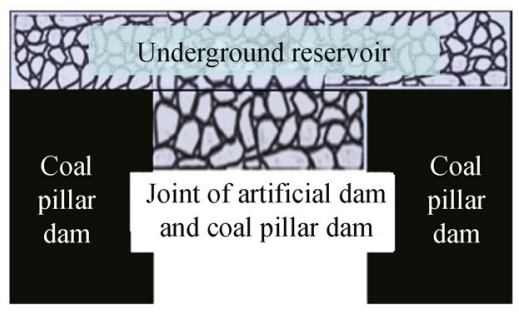

Step 1: cutting on the coal pillar

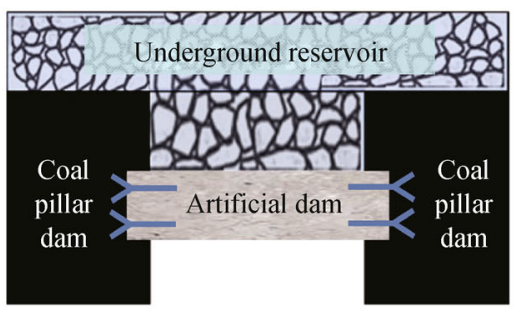

Step 3: pouring the artificial dam

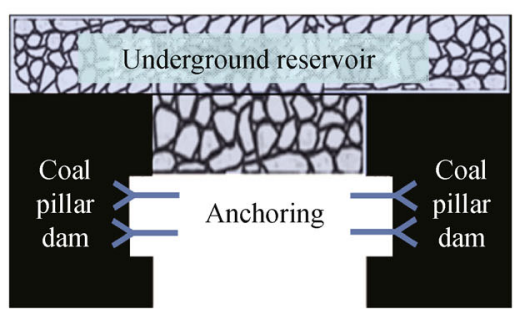

Step 2: anchoring

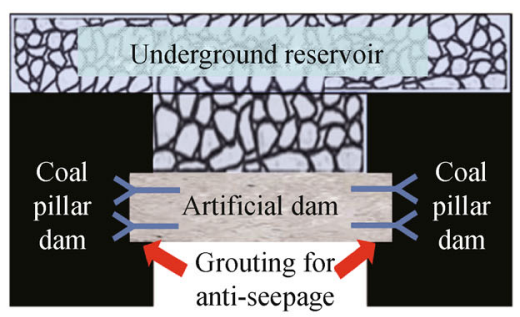

Step 4: grouting for anti-seepage

Figure 8. Construction process of artificial dam. 


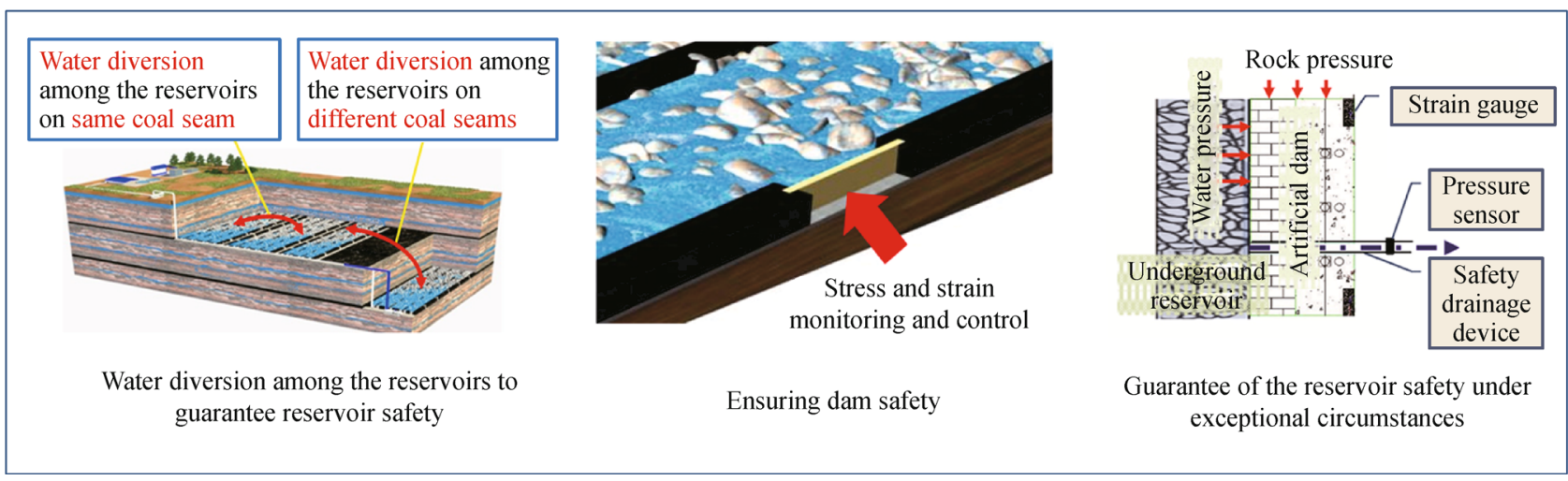

Figure 9. Coal mine underground reservoir safety triple-prevention and control technology.

Table 1

Main Pollutants Removal Effect of Mine Water

\begin{tabular}{lccc}
\hline & Effluent parameters & Reuse Water Standard & Removal ratio \\
\hline Suspended matter $/\left(\mathrm{mg} \cdot \mathrm{L}^{-1}\right)$ & $5-15$ & 30 & $60 \%-95 \%$ \\
$\mathrm{COD} /\left(\mathrm{mg} \cdot \mathrm{L}^{-1}\right)$ & $7.8-31$ & 50 & $60 \%-86 \%$ \\
Total hardness $/\left(\mathrm{mg} \cdot \mathrm{L}^{-1}\right)$ & $206-334$ & 450 & $8 \%-40 \%$ \\
\hline
\end{tabular}

position, purification action of the mine water and the rock masses can be controlled to improve its effect (Table 1).

A coal mine underground reservoir "three-in-one" water quality control technology (Figure 10) has been researched $\&$ developed, which includes filtering and precipitation before the mine water enters the reservoirs, natural purification in the reservoirs, and down hole modular processing. Mine water (it is heavily polluted) modular processing technology has been researched $\&$ developed to ensure underground water safety and efficient mine water resource utilization.

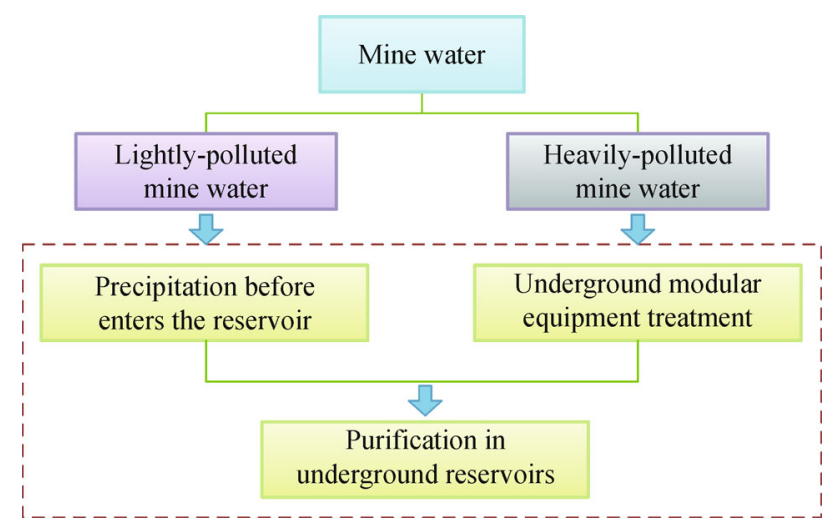

Figure 10. "Three-in-one" mine water quality control technology.

\subsection{Intellectual property rights}

So far, Shenhua has applied for 34 invention patents related to the coal mine underground reservoir technology. In total, 20 have been authorized, establishing a more systematic intellectual property system on the coal mine underground reservoir. The following are major authorized invention patents related to various coal mine underground reservoir technologies. As shown in Table 2.

\section{Demonstration project and commercialization}

\subsection{Construction of demonstration project}

In 1998, Shenhua Group built the first water storage facility in Daliuta Coal Mine in the Shendong Mining Area, with water reserve of $50,000 \mathrm{~m}^{3}$, which proves feasibility of underground storage and utilization of the mine water. The first coal mine underground reservoir composed of multiple mined areas with water reserve of $600,000 \mathrm{~m}^{3}$ was established in 2006 in Daliuta Coal Mine, making a massive storage and utilization of the mine water at a low cost realized. In 2010, the first distributed underground reservoir was built also in Daliuta Coal Mine, with water reserve of $7.1 \times 10^{6} \mathrm{~m}^{3}$, making zero discharge of the mine water realized.

Taking the distributed underground reservoir project (Figure 11) in Daliuta Coal Mine as an example, three underground reservoirs have been built on $2^{-2}$ coal seam, and No. 4 underground reservoir is being constructed on $5^{-2}$ coal seam. A large-aperture drilling technology with large vertical distance, high pressure difference, and high through precision between the reservoirs on the upper coal 
Table 2

Major Authorized Patents Related to the Coal Mine Underground Reservoirs

\begin{tabular}{|c|c|c|}
\hline Technology field & Patent description & Patent No. \\
\hline Water source prediction & $\begin{array}{l}\text { A method for monitoring the dynamic fissures of the mining working face by } \\
\text { miner }\end{array}$ & ZL201210134981.X \\
\hline Reservoir site selection & A method for determining the location of the underground reservoir & ZL201210256970.9 \\
\hline \multirow{2}{*}{$\begin{array}{l}\text { Reservoir capacity calculation and capacity } \\
\text { expansion technology }\end{array}$} & A method for determining capacity of the mine underground reservoir & ZL201210256976.6 \\
\hline & $\begin{array}{c}\text { Cleaning method and equipment for base plate of the air return way of the } \\
\text { working face at super-great mining height }\end{array}$ & ZL201110220548.3 \\
\hline \multirow[t]{3}{*}{ Dam construction } & A distributed underground reservoir and its construction method & ZL201210256979.X \\
\hline & $\begin{array}{l}\text { An artificial water retaining dam of the coal mine underground reservoir and the } \\
\text { connection method with the coal pillar dam }\end{array}$ & ZL201310354100.X \\
\hline & An opencast coal mine underground reservoir & ZL201210473021.6 \\
\hline \multirow[t]{3}{*}{ Safety Guarantee } & An safety monitoring method for the underground mine reservoir & ZL201210473327.1 \\
\hline & $\begin{array}{l}\text { Distributed underground reservoir group and migration methods of the mine } \\
\text { water within the group }\end{array}$ & ZL201210473118.7 \\
\hline & $\begin{array}{l}\text { Detection device, equipment and method for residual capacity of the } \\
\text { coal mine underground reservoir }\end{array}$ & ZL201310303259.9 \\
\hline \multirow[t]{2}{*}{ Water quality control } & A method for distributing storage of underground mine water & ZL201210133605.9 \\
\hline & A method for distribute utilization of underground mine water & ZL201210134162.5 \\
\hline
\end{tabular}

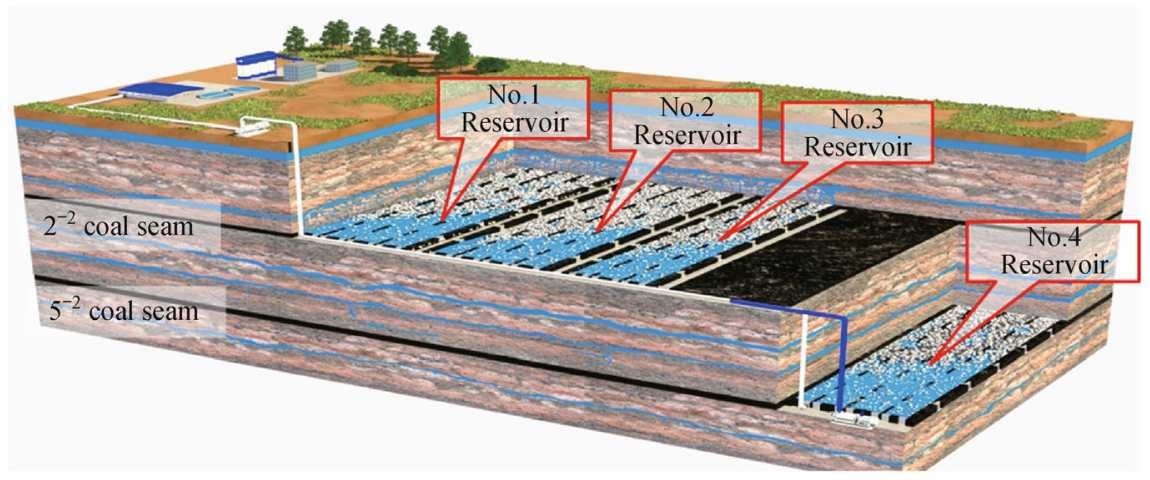

Figure 11. Demonstration project of the distributed underground reservoir in Daliuta Coal Mine.

seam and the lower coal seam has been researched \& developed. A water conveying channel with a diameter of $1.4 \mathrm{~m}$ was first built between the reservoirs with a vertical distance of $155 \mathrm{~m}$ on the upper coal seam and the lower coal seam in Daliuta Coal Mine, and four water conveying and distribution channels were arranged in the channel so that the water diversion between the reservoirs on $2^{-2}$ and $5^{-2}$ coal seams was realized. At present, all underground water in Daliuta Coal Mine comes from the distributed underground reservoir and can be reused. Meanwhile, the production water and the ecological water will be supplied if necessary, so that there is zero discharge of mine water.

\subsection{Commercialization in the Shendong Mining area}

Currently, 35 coal mine underground reservoirs have been built in the Shendong Mining area, with water reserve of $31 \times 10^{6} \mathrm{~m}^{3}$. From 2012 to 2014 , the coal mine underground reservoirs have supplied water of $178.6 \times 10^{6} \mathrm{~m}^{3}$ in total. In
$2014,64.3 \times 10^{6} \mathrm{~m}^{3}$ water has been supplied, which accounts for over $95 \%$ of the total water consumption in the Shendong Mining Area, with annual benefits of more than $800 \times 10^{6} \mathrm{CNY}$. The underground reservoir not only provides a guarantee for production water, domestic water, and ecological water in the worldwide unique 200MTPA mining area, but also supplies the water for the surrounding power stations and will soon supply the water for the coal to liquid project (The daily water supply quantity is 32,000 $\mathrm{m}^{3}$ ). Since the underground reservoir supplies enough water for the restoration of the surface ecology and the surface vegetation, coverage in the mining area has been increased from about $50 \%$ to about $80 \%$ in the latest 5 years.

\subsection{Domestic commercialization}

To apply the technology under different coal seams and water qualities, there are more than 50 underground 
reservoirs. Current reservoirs are being built and will be built in other western mining areas in the future. The Ministry of Land and Resources and National Energy Bureau has listed the coal mine underground reservoir technology as an advanced technology for commercialization. It has proved that the technology could be applied to a wide range of conditions according to the current built projections. It could successfully protect and utilize billions $\mathrm{m}^{3}$ of mine water if the technology was applied on a large scale in western areas and could provide water resource support for the development of society and the economy.

\subsection{Further expansion of the prospect of the application area}

\subsubsection{Application in other mining operations}

Besides coal mining, other mining operations will also generate underground space, so the coal mine underground reservoir technology can also be further extended to these fields.

\subsubsection{Application in pumped storage in western mining area}

There are many wind power and solar power generators in the western areas of China, but the availability is low. Pumped storage is an effective means for energy storage. By utilizing height difference among the underground reservoirs of different coal seams, pumped storage can be realized at a low cost, which could largely improve the utilization efficiency of renewable energies in western mining area (Xie, Hou, Gao, Zhou, \& Gao, 2015).

\subsubsection{Application in international energy development \& cooperation}

The coal mine underground reservoir technology also wins high affirmation from Mr. Harry (Chairman, World Coal Association, CEO of Rino Tinto Energy) and Mr. Palmer (Senior vice president of Peabody Energy, which is the largest coal producer in US). Both of them believe this technology is completely suitable for other major coalproducing countries and can be used for reference. Currently, China is accelerating the implementation of "One Belt and One Road" energy strategy, of which energy cooperation is a key part. Mongolia, central Asia, and west Asia along the "One Belt and One Road" are rich in energies, but highly lack water resources. For this reason, the coal mine underground reservoir technology can contribute to energy development in these areas.

\section{Conclusions and future}

The Western Area has become a major coal producing area in China. The water resource shortage is a major issue of constraining the scientific development of coal in the area. The coal mine underground reservoir technology developed by Shenhua Group provides an important way for realizing harmonic mining of coal and water resources in western China and protecting and utilizing the water resources, thereby having obvious economic and social benefits. If the coal mine underground reservoir technology is widely applied to coal mining in the Western Area of China, billions of mine water produced in coal mining can be effectively protected and utilized every year. Therefore, it will be of great significance on social and economic development of the western mining area.

In the future, Shenhua Group will strengthen the R\&D in protecting and utilizing water resources in coal mining to form complete innovation of the $R \& D$ platform, $R \& D$ verification platform, achievements transformation platform and scientific research collaboration platform. Shenhua Group also aims to largely improve utilization of the mine water in China in the next 5 to 10 years, making contributions for the overall technological level for sustainable mining of coal in China.

\section{References}

BP Global. (2015). BP statistical review of world energy 2015. Retrieved from http://www.bp.com/en/global/corporate/press/speeches/bp-statistical-review-of-world-energy-2015.html.

China National Coal Association. (2013). China coal industry statistical yearbook, 2012. Beijing: China National Coal Association.

Chinese Academy of Engineering. (2012). Consulting project of study on clean, efficient and sustainable development and utilization strategy of China coal. Beijing: Chinese Academy of Engineering.

Gu, D. (2012). Protection and utilization of water resources in coal mining in energy "Golden Triangle". Beijing: Science Press.

$\mathrm{Gu}$, D. (2013a). Water resource protection technology for coal mining in western China. Cornerstone, 1, 61-65.

$\mathrm{Gu}$, D. (2013b). Water resource and surface ecology protection technology of modern coal mining in China's energy "Golden Triangle”. Engineering and Science, 15, 102-107.

Gu, D. (2014). Protection and Utilization of Water Resources in Coal Mining in Western China. 2014 International Pittsburgh Coal Conference.

Gu, D., \& Zhang, J. (2012). Modern coal mining affected to underground water deposit environment in west China mining area. Coal Science and Technology, 40, 114-117.

He, X., Yang, J., Shao, L., Li, F., \& Wang, X. (2008). Problems and countermeasures of mine water resource generation in China. Journal of China Coal Society, 33, 63-66.

Xie, H., Hou, Z., Gao, F., Zhou, L., \& Gao, Y. (2015). A new technology of pumped-storage power in underground coal mine: principle, present situation and future. Journal of China Coal Society, 40, 965972. 